\title{
Teorias de gênero e os movimentos feministas: uma análise sobre Girls
}

Gender theories and feminist movements: an analysis of Girls

\section{Brena 0'Dwyer}

Mestra em Saúde Coletiva pelo Instituto de Medicina Social da Universidade Estadual do Rio de Janeiro e doutoranda em Antropologia Social no Programa de Pós-Graduação em Antropologia Social do Museu Nacional - Universidade Federal do Rio de Janeiro.

Submetido em 18 de Janeiro de 2018 Aceito em 27 de Junho de 2019

\section{RESUMO}

0 artigo apresentado é uma resenha do terceiro episódio da última temporada da série Girls, de Lena Dunham. 0 objetivo é apontar as tensões entre teorias de gênero e movimentos feministas, com o enfoque em produções artísticas realizadas por mulheres, especialmente no que diz respeito a uma especificidade ou essência do ser mulher que refletiria sobre obras realizadas por mulheres.

PALAVRAS-CHAVE: Gênero; feminismo; Girls.

\section{ABSTRACT}

This article is a review of the third episode of the last season of Girls, by Lena Dunham. The main objective is to point to the tensions between gender theory and feminist movement focusing on artistic productions made by women, specially about the specificities of being a woman, which would supposedly reflect in this kind of production. KEYWORDS: Gender; feminism; Girls.

\section{RESUMEN}

El artículo presentado es una reseña del tercer episodio de la última temporada de la serie Girls de Lena Dunham. El objetivo es apuntar las tensiones entre teorías de género y movimientos feministas con el enfoque en producciones artísticas realizadas por mujeres, especialmente en lo que se refiere a una especificidad o esencia del ser mujer que reflexionaría sobre obras realizadas por mujeres.

PALABRAS CLAVE: Género, feminismo, Girls.

Dossiê A Música e suas Determinações Materiais - https://revistaecopos.eco.ufrj.br/ 
Os movimentos feministas e as teorias de gênero têm influências recíprocas e contradições internas. Esse debate reflete na forma como mulheres artistas criam conteúdo e também na recepção dessa "arte feminina". Essas questões são prementes no episódio seis da última temporada de Girls.

O seriado foi criado, dirigido e estrelado por Lena Dunham a partir de 2012, com a última temporada ocorrendo em 2017. O enredo narra a história de Hannahh Horvath, aspirante a escritora que começa a série aos 24 anos perdendo a ajuda financeira dos pais, e suas amigas Marnie, Jessa e ShosHannah. As quatro são jovens de classe alta vivendo em Nova York e lidando com as dificuldades do início da vida adulta.

$\mathrm{Na}$ última temporada do seriado, Hannahh protagoniza um episódio no qual nenhuma das amigas está presente, o que ocorre com frequência no seriado. Neste episódio, Hannah vai à casa de um escritor famoso, a convite dele, sobre quem ela escreveu uma crítica em um site. 0 texto de Hannah diz respeito à denúncia de assédio sexual de uma jovem universitária contra o escritor.

O episódio começa com Hannah andando até o apartamento do escritor, Chuck Palmer. Hannah diz a ele que não pretende ficar e que está surpresa por ele ter encontrado o artigo e querer conversar. Ele responde que não a chamou ali para se desculpar, mas para contar o lado dele da história. 0 episódio é uma conversa entre os dois, na qual Palmer tenta explicar para Hannah como o que aconteceu teve um impacto negativo em sua vida e que ela é uma ótima escritora e deveria se interessar por outros assuntos. Palmer afirma para Hannah que a denúncia feita contra ele é falsa, que o encontro entre os dois foi consensual e que sua única culpa foi não ter querido conhecer a jovem melhor. No fim, ele convida Hannah para ir ao quarto ver livros autografados e convida Hannah a deitar na cama. Ela deita, constrangida, enquanto ele explica que aquele ato não é sexual. Até que ele se vira para ela sem as calças. Nesse momento Hannah inicia o contato sexual, mas logo se arrepende e se levanta. 0 episódio termina com Hannah se afastando do prédio do escritor enquanto outras mulheres vão andando em direção a portaria.

\section{Dossiê A Música e suas Determinações Materiais - https://revistaecopos.eco.ufrj.br/}


O episódio apresenta a questão que aparece para as mulheres artistas: existe uma experiência feminina que pode ser representada? Porque a arte produzida por homens é interpretada como "neutra" enquanto a produzida por mulheres aparece como arte "feminina"? Essa mesma contradição está presente entre o feminismo, a partir da mulher como sujeito político identitário, e os estudos de gênero, com seu papel clássico de questionamento da identidade feminina enquanto tendo bases biológicas ou naturais.

Piscitelli (2009), no artigo "Gênero: a história de um conceito", traça uma trajetória e apresenta um mapa sobre o conceito de gênero. Para a autora, a importância das teorias de gênero é desmontar um duplo processo de naturalização. Por um lado, as diferenças supostamente naturais e inatas entre homens e mulheres e, por outro, a distribuição desigual de poder em razão destas diferenças. Por isso, as autoras feministas usam o termo gênero para referir-se ao caráter cultural das distinções entre homens e mulheres e feminilidade e masculinidade (2009, p.119).

Donna Haraway (2004) narra que o conceito de gênero foi utilizado pela primeira vez pelo psicanalista Robert Stoller para distinguir entre natureza e cultura, vinculando o sexo à biologia e o gênero à cultura. Ainda assim, para Stoller há uma diferença sexual natural no corpo fisiológico, mesmo que algumas pessoas nasçam com a genital de um sexo, mas tenham sua identidade de gênero associada a outro.

Nos anos 1970, as formulações de gênero tiveram impacto e foram reelaboradas em conjunto com o movimento feminista. As feministas utilizaram a noção de gênero como culturalmente produzido para falar da preocupação com as desigualdades sociais entre homens e mulheres, articulando a dimensão teórica para demonstrar que as desigualdades estão na esfera do social e, portanto, podem ser modificadas (Piscitelli, 2009, p.125).

A primeira onda do feminismo ocorreu no final do século XIX e início do XX na Europa e EUA, como uma luta por direitos iguais a cidadania, supondo a igualdade entre os sexos, já que nesse momento as leis eram diferentes para homens e mulheres. As feministas reivindicavam principalmente o direito ao voto, o acesso à educação e a posses e bens. Partiam do slogan "se a subordinação da mulher não é justa, nem natural, como se 
chegou a ela, e como ela se mantém?". Nas décadas de 1950 e 1960, os grupos feministas continuavam lutando pela igualdade de direitos. Em 1949, Beauvoir publica O segundo sexo (1960). Para a autora, eliminar a dominação masculina passava por mais do que modificar as leis, mas enfrentar os aspectos sociais que situavam a mulher em um lugar inferior. Para tal, era preciso modificar a educação que preparava as meninas para agradar os homens, para o casamento e a maternidade; o caráter opressivo do casamento, como obrigação em busca de proteção e não por amor; o fato da maternidade não ser livre; a vigência de um duplo padrão de moralidade; e a falta de trabalho digno para mulheres.

Ninguém nasce mulher: torna-se mulher. Nenhum destino biológico, psíquico, econômico define a forma que a fêmea humana assume no seio da sociedade; é o conjunto da civilização que elabora esse produto... (Beauvoir, 1960)

Esse livro é considerado o precursor da segunda onda do feminismo, que pensava a subordinação das mulheres como histórica e geograficamente situada, mas também como universal, já que ocorre em todas as épocas e períodos históricos. 0 suposto caráter natural dessa subordinação é questionado e surge o entendimento que ser mulher é uma construção social. Assim, as feministas, à época, reivindicam igualdade de direitos e questionam as raízes culturais das desigualdades. Procuram explicar essa subordinação através de categorias como: mulher, opressão e patriarcado.

A ideia de "mulher" enquanto categoria política foi desenvolvida sobretudo nos EUA para demonstrar que a opressão das mulheres está para além de classe e raça, atingindo todas as mulheres, segundo Piscitelli (2009), criando uma identidade que inclui traços biológicos e sociais. A opressão patriarcal estabeleceria uma ligação entre todas as mulheres através do tempo e culturas. Assim, era preciso que as mulheres definissem o que experienciavam como opressivo. A política passava a envolver qualquer relação de poder, mesmo fora da esfera pública. Surge a ideia de que "o pessoal é político", e que as relações amorosas e familiares também precisavam ser repensadas. Essa ideia aparece de maneira revistada no episodio, já que o mote para o encontro é a denuncia de assédio 
sexual e todas as cenas são dentro do apartamento do escritor. Portanto, essa ideia do movimento feminista dos anos 1970 permanece atual.

0 "patriarcado" foi conceituado, na mesma época, como um sistema social no qual a diferença sexual serve como base da opressão e da subordinação da mulher pelo homem. Definido pela capacidade masculina de controlar o corpo da mulher para fins reprodutivos e sexuais, o conceito de patriarcado faz alusão a uma família na qual o pai tem poder sobre os filhos e a esposa. 0 conceito foi sendo utilizado sem atenção para as dimensões históricas e tornou-se vazio e vago, falando de uma opressão naturalizada em termos metodológicos. Apesar de ter surgido para demonstrar que a subordinação feminina não é natural, o conceito de patriarcado perdeu sua definição e força analítica; é nesse contexto que o conceito de gênero surge.

O conceito de gênero se difunde a partir do texto de Rubin, de 1975, "Tráfico de mulheres: notas sobre a economia política do sexo". A autora elabora o conceito "sistema de sexo/gênero", que seria o arranjo através do qual uma sociedade transforma a sexualidade biológica em produtos da atividade humana. A autora entende que a passagem de "fêmea" para "mulher domesticada" ocorre no trânsito entre natureza e cultura no espaço da sexualidade e reprodução.

Segundo Piscitelli (2009), na década de 1980, a identidade política feminina criada pelo feminismo para a reivindicação de direitos começa a ser questionada por feministas negras e mulheres do terceiro mundo. Afirmavam que seus interesses tinham sido apagados pela ênfase na identidade entre mulheres, favorecendo mulheres brancas e de classe alta. Mulheres negras diziam que a discussão sobre direitos reprodutivos não podia estar centrada apenas no aborto, mas também na garantia de que seus filhos já vivos não fossem assassinados. Mulheres de terceiro mundo mostravam que a ênfase na identidade tornava práticas como o uso do véu expressões da opressão masculina, ignorando as relações de desigualdade entre os países.

Haraway (2004) e Piscitelli (2009) demonstram que para essas feministas o foco no gênero obscurecia outras características e diferenças entre mulheres e identificavam que o gênero deveria ser pensado como fazendo parte de um sistema de diferenças.

\section{Dossiê A Música e suas Determinações Materiais - https://revistaecopos.eco.ufrj.br/}


Também surge a crítica da leitura de poder como um par binário entre subordinação e dominação. Esses novos estudos buscavam explorar a subordinação em contextos particulares, entendendo o poder como fluido e posicionando as mulheres segundo lugar e momento histórico, inclusive para pensar as oposições a essas estruturas de dominação.

As novas leituras sobre gênero fazem esforço radical para eliminar qualquer naturalização da diferença sexual. A partir dos anos 1980, sexo e natureza passam a ser pensados como produtos culturais, levando em consideração principalmente pessoas que resistem à classificação binária entre homens e mulheres, como pessoas intersex e travestis e transexuais.

Assim, partindo das críticas teóricas, o movimento feminista precisa repensar o sujeito político "mulher". Interpretando o episódio de GIRLS a partir desse histórico, é possível entrever que a produção feita por mulheres não é essencialmente feminina. Simultaneamente, se o episódio e o seriado em geral retomam a ideia de uma experiência compartilhada entre mulheres, é preciso ressaltar que essa experiência é matizada por outras diferenças como classe e raça. As categorias de subordinação, opressão e patriarcado podem servir para interpretar o episódio de forma política, ainda que no plano teórico tenham sido questionadas pela ideia de uma relação monolítica de poder. Essas categorias funcionam politicamente por negar uma diferenciação entre homens e mulheres determinada pela biologia e favorecer explicações de cunho social.

A diferença é um problema central desde o surgimento do movimento feminista, e foi amplamente discutida nos anos 1960, especialmente no embate entre as correntes à época conhecidas como "feminismo da igualdade" e "feminismo da diferença". As feministas "da igualdade" defendiam a distribuição igualitária de direitos e bens entre homens e mulheres, diminuindo as diferenças entre eles, enquanto as feministas "da difrerença" valorizavam os atributos entendidos como femininos e entendiam que a luta feminista deveria ser para que estes fossem os valores hegemônicos da sociedade, criticando o que consideravam o assimilacionismo da concepção de mundo androcêntrica da primeira linha. Esse segundo caminho foi posteriormente criticado por ser essencialista (Rodrigues, 2009).

Dossiê A Música e suas Determinações Materiais - https://revistaecopos.eco.ufrj.br/ 
Para Rodrigues (2009), a dicotomia entre igualdade e diferença é falsa, sendo a desigualdade o segundo termo da oposição. Ainda comentando a história do feminismo francês, autora demonstra que desde a Revolução Francesa existem dois caminhos na luta pelos direitos das mulheres:

0 primeiro exige que o ideal de cidadania alcançado pelos homens seja estendido às mulheres, de tal forma que a sociedade seja "neutra em termos de gênero". 0 segundo (...) defende que as mulheres têm capacidades, talentos, necessidades e preocupações específicas, que devem ser levados em conta na sua cidadania (...) a lógica da sociedade patriarcal sustentaria que os dois caminhos seriam incompatíveis porque o patriarcado permite apenas que se opte entre duas alternativas: tornar-se mulher "como homens", e assim, sujeito de direitos, ou valorizar a especificidade das mulheres, que não confere nenhum valor para tornálas cidadãs. (2009, p.122).

Assim, o episódio analisado remete a uma questão ontológica e intrinsicamente contraditória na produção feminista: a própria definição de "mulher" enquanto sujeito político do movimento social. 0 movimento feminista tem um passado e presente polifônicos. Os feminismos contemporâneos, em razão dos questionamentos de feministas trans e negras, relembram o debate. Butler (2003) aponta o paradoxo das políticas identitárias que partem da ideia da unicidade do sujeito. Entretanto, a autora argumenta a favor da luta política independente das identidades afixadas.

Preciado (2011) propõe o que chama de uma política de "multidão queer" a partir da noção de que não há qualquer base natural como "mulher" ou "gay" que possa legitimar a ação política. Portanto, o autor defende a "desontologização das políticas de identidades".

Donawerth, no ensaio "Feminisms" (2009), analisa como as demandas feministas e as ficções científicas escritas por mulheres estão conectadas desde o século XVII. A autora traça um correlato entre as reinvindicações dos movimentos feministas e as utopias e distopias criadas nos livros de ficção científica escritos por autoras. Apesar de centrar a análise na literatura de ficção científica, esta correlação é útil para pensar o episódio de Girls nesta chave da relacionalidade entre ficção e demandas feministas. 
Especificamente sobre o conteúdo do episódio, que trata de uma jovem feminista fazendo uma crítica a um cânone da literatura não pelo que ele escreve, mas pelas atitudes, além de mostrar como o processo de denúncia é cruel e muitas vezes fica circunscrito aos próprios círculos feministas, fora deles as acusações são entendidas como levianas. Assim, apesar de ser um episódio em uma série de ficção, trata de questões atuais dos debates feministas e também de temas que são perenes ao longo da história do movimento, como a noção de que o pessoal é político. 0 episódio trata ainda da importância da não culpabilização da vítima, tema central nos feminismos contemporâneos.

Outra questão tratada no episódio e nos debates feministas atuais é a de uma dimensão posterior do trauma: ainda que a relação sexual entre o escritor e a jovem tenha sido consensual no momento do acontecido, ela pode ser repensada depois.

O fim do episódio mostra Hannah se afastando do prédio, enquanto outras mulheres jovens se aproximam da portaria do escritor, como em uma espécie de aviso: o feminismo tem algumas vitórias, mas ainda é necessário. Os debates apresentados no episódio, analisado à luz das teorias de gênero e demandas do movimento feminista, mostram que as experiências de mulheres são muitas e distintas, não podendo ser reduzidas a biologia ou a reprodução. Scott, em 1995, atentava para como as categorias de "homens" e "mulheres" são ao mesmo tempo vazias e transbordantes. Vazias justamente porque não têm significado transcendente ou essencial, mas transbordantes porque mesmo quando parecem fixas, contêm outras definições alternativas.

\section{Referências bibliográficas}

BEAUVOIR, Simone. O segundo sexo: a experiência vivida. São Paulo: Difusão Européia do Livro, 1960.

BUTLER, Judith. Problemas de gênero: feminismo e subversão da identidade. Rio de Janeiro: Civilização Brasileira, 2003.

DONAWERT, J. "Feminisms". In: Bould, M., Butler, A., Roberts, A., Vint, S. The Routledge Companion to Science Fiction. Taylor and Francis, 2009. 
HARAWAY, Donna. “'Gênero' para um dicionário marxista: a política sexual de uma palavra”. In: Cadernos Pagu (22). Campinas: Unicamp, 2004.

O'DWYER, Brena; RIBEIRO, Letícia e HEILBORN, Maria Luiza. "Dilemas do feminismo e a possibilidade de radicalização da democracia em meio às diferenças: considerações a partir da Marcha das Vadias do Rio de Janeiro". In: Revista Civitas, no prelo.

PISCITELLI, Adriana. "Gênero: a história de um conceito". In: ALMEIDA, Heloísa. B.; SZWAKO, José E. Diferenças, igualdade. São Paulo: Berlendis \& Vertecchia, 2009.

PRECIADO, Paul Beatriz. Multidões queer notas para uma política dos "anormais". Estudos Feministas, Florianópolis, v. 19, n. 1, p. 11-20. Jan./abr. 2011.

RODRIGUES, Carla. Coreografias do feminino. Florianópolis, Editora Mulheres, 2009

RUBIN, Gayle. "O Tráfico de Mulheres: notas sobre a "economia política" do sexo". Recife: SOS Corpo, 1993.

SCOTT, Joan. "Gênero: uma categoria útil de análise histórica”. Educação \& Realidade, v. 20, no 2, Porto Alegre: UFRGS, 1995.

SAFFIOTI, H. Conceituando o gênero. In: RODRIGUES, C. et all (org). Problemas de gênero. Funarte. 2016. 